\title{
DA EXPERIÊNCIA ESTÉTICO-TELEOLÓGICA DA NATUREZA À CONSCIÊNCIA ECOLÓGICA: UMA LEITURA DA CRÍTICA DO JUÍZO DE KANT
}

\author{
Leonel Ribeiro dos Santos ${ }^{1}$
}

- RESUMO: O objetivo deste ensaio é propor uma interpretação daquilo que para muitos intérpretes constitui o enigma e a dificuldade maior da terceira Crítica de Kant: o fato de o filósofo remeter para a mesma faculdade do espírito (a faculdade de julgar - Urteilskraft) e para o mesmo princípio transcendental de apreciação (a teleoformidade ou conformidade a fins - Zweckmässigkeit) o fenômeno da arte humana e os fenômenos da natureza organizada - a estética e a teleologia. Na leitura que propomos, tentamos perceber a fecundidade dessa estranha associação ("associação barroca", no dizer de Schopenhauer) precisamente para permitir pensar alguns dos problemas que coloca atualmente a racionalidade ecológica, não aquela que visa excluir o homem da natureza como seu inimigo, mas uma consciência ecológica que defenda uma natureza viva com homens sensíveis, com seres humanos tais que não pensam já a sua relação com a natureza como sendo uma relação de meros "senhores e possuidores" frente a um objeto inerte e destituído de valor e de significação por si mesmo, mas que são capazes de contemplar e apreciar a natureza como valiosa por si mesma, de reconhecê-la como um sistema de sistemas finalizados e de colaborar na sua preservação, que têm até perante ela genuínos sentimentos de admiração pela sua beleza, de respeito pela sua sublimidade e de gratidão pela sua exuberância e favores. Em suma, propomo-nos mostrar a nova atitude perante a natureza que se deixa pensar a partir da Crítica do Juízo, considerada esta obra na sua complexidade sistemática.

- PALAVRAS-CHAVE: Kant; Crítica do Juízo; teleologia; filosofia e ecologia.

1. No Apêndice à sua obra principal, O mundo como vontade e representação, de 1818, Schopenhauer faz uma apreciação crítica das mais im-

\footnotetext{
1 Leonel Ribeiro dos Santos é docente da Universidade de Lisboa.
} 
portantes obras filosóficas de Kant e dedica aí também algumas páginas à Crítica do Juízo, obra onde Kant aborda os problemas estéticos e os problemas da natureza orgânica, por conseguinte, a estética e a teleologia. Referindo-se à idéia que Kant teve de unir na sua terceira Crítica, sob um mesmo princípio filosófico, essas duas realidades que sempre haviam sido tratadas separadamente pelos filósofos, o filósofo de Danzig diz tratar-se de uma "união barroca" (barocke Vereinigung) de dois domínios heterogéneos, no que vê mais uma prova da irresistível tendência de Kant para forçar a realidade a entrar nas suas simetrias arquitetônicas (Schopenhauer, 1977, p.647). O autor das três Críticas podia assim ver por fim todos os princípios da sua filosofia reconduzidos às três faculdades fundamentais do espírito o entendimento, a razão e o juízo reflexionante -, cabendo a esta última dar conta não só da apreciação estética da arte e da natureza como também da consideração teleológica da natureza, mediante o seu princípio de finalidade ou de conformidade a fins (Zweckmässigkeit).

Pela mesma época, houve um outro contemporâneo de Kant que terá intuído com agudeza o que teria tido em mente o autor da Crítica do Juízo ao associar nela a arte e a natureza sob um mesmo princípio de compreensão, e que terá percebido as fecundas consequências dessa aparentemente estranha associação. Esse contemporâneo foi Goethe. Num apontamento acerca da influência que sobre ele exercera a filosofia da sua época e no contexto de uma avaliação da sua relação com a filosofia de Kant, escreve o autor do Fausto:

Chegou depois às minhas mãos a Crítica do Juízo, à qual devo um dos períodos mais felizes da minha vida. Aqui vi as minhas ocupações mais díspares postas uma junto da outra; os produtos da arte e da natureza considerados do mesmo modo; o juízo estético e o juízo teleológico iluminando-se mutuamente... Alegrava-me que a arte poética e a ciência natural comparada fossem tão afins uma da outra, e que ambas estivessem subordinadas à mesma faculdade de julgar... Contudo, entre os kantianos encontrei pouco acordo tanto relativamente ao que eu tinha assimilado como em relação ao modo como o tinha assimilado... Eles ouviam-me, mas nem eram capazes de me fazer objeções nem de me ajudar. (Goethe, 1993, p.66) ${ }^{2}$

Não é aqui o lugar para averiguar quais os tópicos da referida obra de Kant que poderão ter sido assim tão sugestivos para um tão distinto leitor como foi Goethe, o qual juntava à profundidade e alcance da intuição esté-

2 Cf. J.W. von Goethe, "Einwirkung der neueren Philosophie" (1817), publicado em Zur Morphologie, I, 2, 1820 (existe uma trad. portuguesa em Goethe, 1993). Veja-se também a carta de Goethe a Zelter, de 29 de Janeiro de 1830: "Es ist ein grenzenloses Verdienst unseres alten Kant,... dass er in seiner Kritik der Urteilskraft Kunst und Natur nebeneinanderstellt und beiden das Recht zugesteht: aus grossen Prinzipien zwecklos zu handeln". 
tica a intensa curiosidade do investigador da natureza. Mas alguns saltam à vista, como é o tema da analogia das formas naturais que irresistivelmente levam o naturalista que sobre elas reflete a pressupor uma imagem originária (Urbild) ou esquema (Schema) comum da sua geração e uma força formadora da originária mãe (Urmutter) comum natureza, tema que Kant aborda expressamente no $\S 80$ da sua terceira Crítica, a idéia, por conseguinte, de uma arte ou "técnica da natureza" pensada por analogia com a arte humana e mediante a qual a natureza é representada na produção espontânea das suas criaturas como se fosse conduzida por uma força formadora intencional, enquanto, por outro lado, a genuína arte humana, que é obra do gênio, é também pensada como sendo um produto espontâneo da natureza agindo através das faculdades do espírito.

Com muito raras excepções, as interpretações da terceira Crítica de Kant não seguiram a pista sugerida por Goethe, mas antes confirmaram o juízo de Schopenhauer. Os intérpretes que dela se ocuparam ora se fixaram na sua primeira parte (crítica do juízo estético), ora na segunda parte (crítica do juízo teleológico), como se se tratasse de fato de dois domínios realmente distintos e não comunicáveis entre si, ou cuja comunicabilidade era tão problemática que tê-la em conta só dificultava a abordagem de cada um dos respectivos problemas. A questão da relação entre as duas partes, que Kant tenta esforçadamente justificar nas duas longas introduções que escreveu para a obra, quando expressamente abordada, é-o com desconforto, como se estivesse envolta numa certa obscuridade, o que, de resto, também o próprio filósofo parece reconhecer no enigmático penúltimo parágrafo do Prefácio da sua obra. Os efeitos desta estratégia hermenêutica têm-se feito sentir não só na impossibilidade de aceder verdadeiramente à compreensão da sistematicidade duma obra que tem justamente a dimensão e a pretensão sistemática (tanto a da própria filosofia como a da natureza e a do espírito humano) por tema nuclear, como impediu também que se compreendesse a peculiar pertinência da visão kantiana da teleologia da natureza e até a singularidade da doutrina estética de Kant. Nomeadamente, perdeu-se quase por completo o sentido da importância dum tópico que realiza a mediação entre as duas partes da obra, o qual é o reconhecimento da primazia matricial e do privilégio que, no contexto da sua análise do juízo estético, Kant concede à experiência estética da natureza como protoexperiência humana. ${ }^{3}$

No presente ensaio, seguindo a pista indicada por Goethe, eu gostaria, em primeiro lugar, de tentar perceber o que terá levado Kant a associar, na

3 Só recentemente este tópico se tornou objeto da atenção de alguns intérpretes. Para um estado da questão, veja-se o nosso ensaio Santos, 2001. 
sua terceira Crítica, os dois referidos domínios sob um mesmo princípio e uma mesma faculdade do espírito; seguidamente, de reconhecer as consequências que tem essa associação, seja para a sua doutrina estética, seja para a visão da natureza que assim se torna possível; finalmente, de avaliar o interesse que pode ter isso para iluminar os atuais debates em torno da consciência ecológica, na medida em que eles requerem uma nova filosofia da natureza a qual não só não deve fazer economia da vivência estética da natureza como pode até ser extraordinariamente potenciada por esta vivência.

2. A tese que me proponho expor é a seguinte: o que permite a Kant a ligação do domínio da arte com o da natureza - da estética com a teleologia - é o peculiar lugar que, na sua doutrina estética, ocupa a experiência estética da natureza, em particular, a vivência da beleza da natureza. Este aspecto é importante, antes de mais, para a compreensão kantiana dos fenômenos estéticos, inclusive os da arte humana. Mas ele permite pontes para outros domínios da filosofia kantiana, nomeadamente, para a experiência moral e a experiência religiosa, e tem consequências sobretudo no modo de entender a natureza e a relação do homem com ela. Graças a isso torna-se possível superar a visão mecanicista, estabelecida como paradigma pela ciência e filosofia modernas, segundo a qual não só a beleza fora eliminada da natureza, como esta se viu destituída de qualquer valor autónomo e reduzida a mero objeto para a legislação do entendimento, para os desígnios do arbítrio humano e satisfação dos seus interesses.

Se é certo que a filosofia teorética de Kant vem confirmar, e também confinar, a legitimidade desse programa da Modernidade, no que respeita à natureza formaliter spectata, reduzindo-a a um corpo de leis de objetividade que o entendimento lhe prescreve a priori (Kant, 1959-2002; Prolegomena § 36, Ak IV, pp.318-320), também é verdade que, por outro lado, em muitos aspectos do pensamento kantiano, se pode reconhecer o culminar de um amplo movimento especulativo de reação ao processo de "desencantamento do mundo" que fora levado a cabo pelos filósofos e cientistas dos séculos XVII e XVIII, os quais haviam reduzido a natureza a um previsível e controlável mecanismo de relojoaria. A leitura extensiva dos escritos de Kant revela que se cruzam neles vários conceitos de natureza que não são de modo nenhum redutíveis àquele que o § 36 dos Prolegómenos tipifica com toda a clareza. Um desses outros conceitos de natureza é aquele que se declina em registo estético e que surpreendemos já nas mais antigas reflexões de Kant acerca da gênese e estrutura do cosmos sob os traços de uma visão barroca da natureza, caracterizada pela exuberância esbanjadora (Verschwendung), pela extraordinária riqueza e fecundidade (Fruchtbarkeit), pelo poder inesgotável de metamorfose e de criação contínua. Aí se fala já duma "secreta arte" (geheime Kunst) da natureza e das "obras de arte 
da natureza" (Kunstwerke der Natur) que são os seus produtos, os quais se oferecem à admiração silenciosa (stilles Erstaunen) e ao prazer (Vergnügen) do homem que os contempla (Kant 1959-2002; Allgemeine Naturgeschichte und Theorie des Himmels, Ak I, p.315, pp.318-319, p.367). E tudo isto no contexto de uma visão do cosmos em grande escala como sendo um vasto sistema de sistemas em contínuo processo de formação regido por uma economia que incessantemente faz sair a ordem a partir do próprio caos. Esta intuição juvenil, exposta numa obra de temática cosmológica onde se fundem intimamente as preocupações científicas com as teodiceicas, ético-antropológicas e estéticas, tem a sua réplica e a sua tardia legitimação na Crítica do Juízo, obra onde o filósofo esclarece a pertinência da visão sistemática não já apenas do cosmos no seu todo, mas também da natureza, tanto no seu todo como nas suas partes e, de modo particular, na incontável variedade das suas formas e dos seus seres organizados. É nesta última Crítica que igualmente se dá razão do peculiar sentimento de prazer que acompanha tal visão sistemática da natureza, em que esta se revela, ao homem que a contempla ou que sobre ela reflete, como um vasto e complexo sistema de fins. Entretanto, nos escritos kantianos da década de sessenta haviam encontrado amplo eco as reflexões de alguns filósofos ingleses (Shaftesbury, Hutcheson, Addison, Edmund Burke) que apontavam no sentido de resgatar a natureza da mera consideração científica e utilitária tornando-a objeto de um sentimento estético, promovendo o gosto mesmo pela natureza selvagem e agreste ou pelos jardins em que a natureza era tratada como se fosse abandonada aos seus próprios ritmos. Pela mesma época, Kant encontrava nos escritos de Rousseau (La Nouvelle Heloïse, Émile) uma concepção da natureza de matriz estóica, uma natureza materna, boa e providente, saturada de significação religiosa, moral e estética. Tenha-se presente a sugestiva descrição do espetáculo da natureza que constitui o cenário em que o vigário de Sabóia dá ao jovem Emílio a sua lição de teologia natural e de moral (Rousseau, 1969, p.401), ou a da experiência da escalada das montanhas alpinas como se se tratasse de uma vivência de arrebatamento físico, psicológico e moral (Rousseau, 1967, pp.4349), ou ainda a que o promeneur solitaire faz da sua vivência da natureza como uma "contemplação pura e desinteressada" com todos os ingredientes de uma experiência mística de "êxtase" e de embriagues (Rousseau, 1964, p.125 ss). E a estas reflexões dos filósofos moralistas e estetas da natureza vêm ainda juntar-se as dos novos naturalistas (Lineu, Buffon, Blumenbach), que já não constatavam só, como os físicos matemáticos mecanicistas, a simplicidade e a regularidade do mecanismo da natureza, mas cada dia descobriam a mais extrema variedade e a mais surpreendente espontaneidade associadas à mais admirável economia, sistematicidade e mútua conveniência. 
Para a terceira Crítica de Kant confluem e nela se cruzam e entretecem todos estes vários aspectos e tendências do pensamento naturalista do século. E a obra, que começou por pretender ser apenas uma "crítica do gosto", acabou por assumir uma arquitetura complexa que liga muitos fios, mobilizando por assim dizer todo o sistema orgânico das faculdades do espírito. Em primeiro lugar, dando conta da peculiar estrutura e natureza do juízo estético e da sua irredutibilidade a um juízo lógico-cognitivo ou a um juízo moral, mas, seguidamente, mediante a aplicação, por analogia, do procedimento técnico da faculdade de julgar às formas e produtos da natureza, esclarecendo a peculiar pertinência ou finalidade com que eles se revelam ao espírito que os contempla ou os investiga; depois, ainda, tentando mostrar como a visão teleológica da natureza, que assim se oferece ao espírito, é compatível com a explicação mecânica e científica da natureza e como, na verdade, deve mesmo ser pressuposta por esta última, se é que também esta pretende ter um sentido; por fim, fazendo ver como a visão teleológica da natureza se liga com a visão teleológica do mundo moral. Obra sistemática por excelência, não admira que os densos parágrafos das duas introduções que o seu autor para ela escreveu tenham a noção de sistema por principal assunto. O elo que liga todas estas seções é o princípio de teleoformidade ou "conformidade a fins" (Zweckmässigkeit), atribuído à faculdade de julgar reflexionante. Este princípio ora é pensado como tendo um sentido meramente subjetivo e formal (no juízo estético a respeito das formas belas da natureza ou da arte), ora também como tendo um sentido objetivo e real, como acontece na apreciação que fazemos dos produtos organizados da natureza, os quais só são pensáveis, não só na sua aparência exterior como sobretudo na sua íntima estrutura e possibilidade mesma, como se a natureza, ao produzilos, o fizesse tendo em vista um fim que ela mesma se propõe, permanecendo todavia para nós desconhecido se ela age efetivamente propondo-se fins e quais os fins que se propõe. Tanto num caso como noutro, o que está envolvido é um juízo de reflexão mediante o qual o sujeito dá um sentido aos objetos da sua contemplação estética ou da sua representação teleológica.

A complexa arquitetônica da terceira Crítica sustenta-se graças a uma intrincada e fina rede de analogias que têm por matriz a estrutura do juízo estético acerca da beleza da natureza. Pode, pois, dizer-se que esta obra de Kant sistematiza o vário reconhecimento de todo um século de meditação a respeito do valor e significado estético da natureza e que ela representa de algum modo até o que se poderia chamar a sagração estética da natureza. Enquanto outros pensadores setecentistas registaram o seu sentimento da natureza, declamaram efusões líricas ou confessaram as suas vivências sublimes, o filósofo crítico propôs-se fazer a anatomia do juízo estético a respeito da natureza e tornar patente o que nesse peculiar juízo está envolvido. O que se passa em nós quando apreciamos esteticamente a natureza? Por- 
que nos fala a natureza ao nosso sentimento do belo e do sublime? Que natureza é essa que assim se nos revela? Que relação de solidariedade tem a experiência estética da natureza com as outras modalidades da experiência humana, como a experiência moral, a experiência religiosa, a experiência científica, filosófica e metafísica?

3. Mais do que qualquer outra obra de Kant, a terceira Crítica tenta estabelecer pontes e mediações e gerir desequilíbrios e compensações (entre o belo e o sublime, entre estética e teleologia, entre arte e natureza, entre teleologia da natureza e teleologia moral), e está construída como uma complexa rede de raciocínios analógicos, sob o modo do como se (als ob). Partindo da evidência do processo intencional da ação racional, de que se tem experiência na fabricação humana de artefatos (arte humana), Kant aplica esse mesmo procedimento como esquema para poder pensar o modo como a natureza produz as suas formas a que chamamos belas e sobretudo os seres organizados, embora esteja consciente de que a natureza não pode ter uma intenção na sua produção ou que, pelo menos, não podemos saber se a tem e qual ela seja. Pelo contrário, precisamente porque é natureza, presumimos que ela age espontaneamente, ao passo que o homem, enquanto ser racional, realiza as suas ações propondo-se fins. O filósofo dá-se conta de que certos produtos da natureza só podem ser pensados, quanto à sua forma e aparência, como se a natureza imitasse a arte humana ou antes uma arte sobre-humana, como se ela mesma fosse artista, ou como se um secreto artista através dela produzisse as suas obras que reputamos como verdadeiras obras de arte da natureza, as quais apreciamos também pela sua bela forma no juízo estético. Mas Kant dá um passo mais e estende a analogia à própria produção interna dos seres naturais, considerando-os não já apenas na sua forma e aparência mas também na sua estrutura e possibilidade interna e, nesse caso, teríamos de pensar a natureza como se ela tivesse uma intencionalidade ou finalidade objetiva e real como condição da possibilidade de tais seres.

No centro e na base desta complexa rede de analogias está um conceito fundamental, desenvolvido por Kant sobretudo na primeira Introdução à sua Crítica do Juízo e também presente nesta obra - o de "técnica da faculdade de julgar" (Technik der Urteilskraft) - a idéia de que a faculdade de julgar tem como característica uma modalidade de procedimento a que Kant chama "técnico" e que aplica à natureza sob a designação de "técnica da natureza" (Technik der Natur). Esta singular expressão, criada por Kant e bem pouco estudada pelos comentadores do seu pensamento estético, ${ }^{4}$

4 Entre as excepções, Lehmann, 1969, pp.289-294. 
evoca hoje um significado que está nos antípodas daquele que Kant lhe atribuiu. Faz-nos pensar num procedimento ou modo de produção mecâniCos, ao passo que com ela Kant pretendia precisamente nomear um modo de produção não mecânico e identificar o tipo de procedimento que está envolvido na criação poética ou artística (Kant 1959-2002; Erste Einleitung in die Kritik der Urteilskraft, VII, Ak, XX, p.219). Por isso, Kant aplicava esse conceito à produção artística e à compreensão da sua lógica específica ou às produções da natureza que são de tal ordem que parecem revelar uma intencionalidade (como se visassem um fim na sua produção, pois o resultado dessa produção se revela pertinente) e, ao mesmo tempo, manifestam uma total espontaneidade, como se a natureza livremente inventasse os seus produtos (não seguindo nenhum esquema ou conceito predeterminado). É este peculiar procedimento de uma finalidade espontânea ou não intencional que Kant designa pelo oxímoro "Zweckmässigkeit ohne Zweck": uma conformidade a fins sem um fim, isto é, uma espontânea e recíproca conveniência dos elementos de um todo que revela a forma ou a estrutura deste como pertinente, rica de sentido e viável. A idéia de uma "técnica da faculdade de julgar" e de uma "técnica da natureza" está, pois, associada diretamente à experiência da criação, da invenção ou produção espontâneas, aconteçam elas na arte humana ou na arte da natureza (no sentido em que só conseguimos pensar os produtos desta como sendo-o de um procedimento análogo ao da arte). A diferença reside em que na arte humana essa técnica é consciente, pelo menos parcialmente, na medida em que o artista tem alguma idéia, por vaga que seja, do que pretende realizar e, por isso, a sua produção é também intencional e finalizada (isto é, ele dispõe os meios para atingir a realização da sua idéia). Nas produções da natureza, porém, essa técnica é, pelo menos tanto quanto podemos presumi-lo, inconsciente e não intencional. E, todavia, para o sujeito que as aprecia, ela só pode ser pensada como se fosse intencional, como se a natureza procedesse superiormente dirigida pelo princípio da "Zweckmässigkeit der Natur" (da teleoformidade ou conformidade a fins - da natureza), embora saibamos que esse princípio é tão somente um princípio da faculdade humana de julgar, a qual, na sua reflexão, o aplica aos produtos da arte humana e aos da suposta arte da natureza (ibidem). É em torno deste pressuposto que se move toda a Crítica do Juízo e é daqui que nascem as analogias entre a arte e a natureza, que nos levam a interpretar a natureza como arte e a arte como natureza.

Graças ao seu novo conceito de uma "técnica da natureza" (que prefiro traduzir por poética da natureza), Kant resolve uma antiga antinomia que percorre toda a história do pensamento, protagonizada por Platão e Aristóteles, a qual opunha a arte e a natureza, atribuindo-se a primazia ontológica e lógica ora a uma ora a outra. Resolve-a, porém, de uma forma paradoxal, pois os dois termos se tornam paradigma um do outro e servem, à vez, para 
reciprocamente se explicarem: a arte autêntica, para sê-lo, deve parecer natureza ou como se fosse natural, mesmo que saibamos que é produto do artifício intencional de um agente; e a natureza, seja no juízo estético ou no juízo teleológico, tem de ser apreciada como se fosse artística e produto de uma arte (por certo não humana), ou como sendo ela mesma artista. O que permite esta convertibilidade dos termos arte e natureza? Na verdade, Kant opera aqui com a ambiguidade do conceito de natureza: é o modo de produzir que atribuímos à natureza o que Kant transpõe para o modo de entender a produção da arte humana, da mesma forma que é o modo segundo o qual pensamos a produção da arte humana o que atribuímos à natureza. Ora, natureza e arte trocam entre si modalidades de produção antitéticas: a natureza dá à arte a espontaneidade da produção, enquanto a arte empresta à natureza a intencionalidade. Tudo isto, é claro, se passa no plano de um juízo de analogia e do como se. Escreve Kant:

Num produto da bela arte temos de estar conscientes de que ela é arte e não natureza; mas, contudo, deve a conformidade a fins na sua forma parecer tão livre de toda a coação de regras voluntárias como se ela fosse um produto da mera natureza. É sobre este sentimento da liberdade no jogo dos nossos poderes de conhecimento, que ao mesmo tempo tem de ser conforme a fins, que se funda aquele único prazer que pode ser universalmente partilhado sem se fundar em conceitos. A natureza era bela, se ao mesmo tempo ela parecia como arte; e a arte só pode ser chamada bela, se estamos conscientes de que ela é arte, e todavia nos parece como natureza. (Kant 1959-2002; KdU§ 45, Ak V, p.306) ${ }^{5}$

No sistema das artes do seu tempo, Kant encontra uma forma de arte que realiza esta simbiose de natureza e arte. Trata-se da arte dos jardins (Gartenkunst, Lustgärtnerei), que ele classifica já entre as belas artes como uma espécie de pintura, feita não com objetos naturais representados, mas com os objetos mesmos da natureza (árvores, arbustos, relva e flores da floresta e do campo), com a finalidade de produzir um quadro para a contemplação dos olhos e do espírito (idem; idem §51, Ak V, p.323). Kant pensa nos jardins "segundo o gosto inglês", onde a natureza, sendo embora obra da arte, não é contudo submetida à violência de uma estrita regularidade, mas trabalhada como se fosse deixada à sua própria espontaneidade, e assim

5 "An einem Producte der schönen Kunst muss man sich bewusst werden, dass es Kunst sei und nicht Natur; aber doch muss die Zweckmässigkeit in der Form desselben von allem Zwange willkührlicher Regeln so frei scheinen, als ob es ein Product der blossen Natur sei. Auf diesem Gefühle der Freiheit im Spiele unserer Erkenntnissvermögen, welches doch zugleich zweckmässig sein muss, beruht diejenige Lust, welche allein allgemein mittheilbar ist, ohne sich doch auf Begriffe zu gründen. Die Natur war schön, wenn sie zugleich als Kunst aussah; und die Kunst kann nur schön genannt werden, wenn wir uns bewusst sind, sie sei Kunst, und sie uns doch als Natur aussieht". 
oferecida como espectáculo ao mero livre jogo da imaginação. É graças a isso que ela proporciona ao espírito de quem a contempla uma constante fonte de gratas surpresas. Pelo contrário, a rígida regularidade e a uniforme simetria são contrárias ao ponto de vista estético e, em vez de proporcionarem ao espírito um verdadeiro prazer, provocam-lhe antes cansaço e aborrecimento. A percepção de que no objeto da contemplação há vestígios da coação e da violência das regras segundo as quais foi produzido inviabiliza mesmo qualquer experiência estética (idem; idem, Ak V, pp.242-3). Somente na medida em que a natureza nos aparece revelando-se espontânea e pródiga em toda a sua variedade e até na sua opulência e aspectos selvagens, sem que nisso pareça estar submetida à regularidade de um mecanismo ou à coação de regras artificiais, é que ela pode proporcionar um alimento inesgotável para o gosto e prazer estéticos de quem a contempla. No jardim, tudo tem de ser não só natureza como também parecer natural, mesmo que saibamos que é somente um produto da arte humana em que a matéria é a própria natureza. A poética kantiana do jardim condensa toda a estética kantiana e pode dar-nos também uma amostra da filosofia da natureza que a partir da experiência estética se torna possível. E isto torna-se mais claro ainda se confrontarmos a filosofia da natureza que se depreende desta poética kantiana do jardim com a filosofia mecânica da natureza e do próprio homem que Descartes expõe no seu L'Homme, servindo-se de exemplos tirados dos artefatos e respectivos mecanismos que existem "nos jardins dos reis" (Descartes, 1988, p.390).

Há assim, no pensamento estético de Kant, uma inequívoca preponderância da natureza sobre a arte, a qual se revela ou insinua por muitos modos. Mas esta preponderância ou pura e simplesmente não tem sido notada pelos comentadores, ou, quando notada por alguns, tem sido interpretada como algo perturbador e negativo, como um resíduo duma teologia da criação, que ameaça a autonomia da arte e do juízo estético que o filósofo crítico por outro lado pretendia legitimar (Gadamer, 1977, pp.39-40). Aqui, em contrapartida, tomá-la como um elemento perturbador sim, mas igualmente como um antídoto contra a redução da estética às malhas duma subjetividade fechada sobre si mesma e sobre as suas vivências ou criações. Mas encaramo-la sobretudo pela fecundidade que revela para iluminar a complexidade dos problemas. E um deles é a concepção do gênio. Para o filósofo, a genuína arte humana é a arte do gênio e por gênio entende ele aquele que produz graças a um talento inato que atribuímos à natureza. O gênio é um "favorecido da natureza" (Günstling der Natur), que possui uma "disposição inata do ânimo (ingenium) mediante a qual a natureza dá a regra à arte" (Kant 1959-2002; KdU, Ak V, p.307). Mas, se a natureza ilumina a arte, também a arte ilumina a natureza. Porventura, tudo nesta se produz apenas mediante o mero mecanismo, sem que a essa produção presida a representação 
de um fim e, todavia, para podermos pensar certos produtos da natureza, seja na sua forma ou na sua estrutura, segundo o nosso modo de representação, só podemos fazê-lo supondo que a natureza procede artisticamente, ou seja, finalizadamente. E isso é ainda mais necessário se não falamos apenas das formas belas da natureza que se oferecem à nossa contemplação, mas dos seus produtos orgânicos que se oferecem à nossa apreciação teleológica. Aí, diz Kant, "a natureza não é só apreciada enquanto parece como arte, mas na medida em que ela é realmente arte (embora sobre-humana)" (idem; idem, p.311). A tal ponto que não pode sequer ser imitada pela arte humana (idem; idem § 64, Ak V, p.371). Num outro passo da obra, Kant prolonga esta idéia da analogia entre a natureza e a arte, precisando-a e sublinhando ainda mais a vantagem da natureza:

Diz-se muito pouco da natureza e da faculdade que ela revela nos seus produtos orgânicos, quando designamos esta como analogon da arte; pois aí se pensa o artífice (um ser racional) como estando fora dela.[...] Talvez alcancemos uma perspectiva mais correta desta propriedade impenetrável se a designarmos como um analogon da vida.[...] Para falar com rigor, a organização da natureza não tem nisso nenhuma analogia com qualquer causalidade que conheçamos. A beleza da natureza pode com razão ser designada como um analogon da arte, já que ela é atribuída aos objetos somente em relação à reflexão sobre a intuição externa dos mesmos, por conseguinte, somente por causa das formas superficiais. Mas a íntima perfeição natural, tal como a possuem aquelas coisas que são possíveis apenas enquanto fins naturais e que, por isso, se chamam seres organizados, essa não pode ser pensada e explicada segundo nenhuma analogia com qualquer propriedade física, isto é, natural, que conheçamos e nem mesmo através de uma analogia perfeitamente adequada com a arte humana, já que nós próprios pertencemos à natureza no mais amplo sentido. (idem; idem § 65, Ak V, pp.374-5)

Movemo-nos, pois, num paradoxo: como pretende aquele, que é apenas uma parte, aplicar a lógica do seu modo peculiar de produzir ao todo de que é ele mesmo produto? Em suma, Kant acaba por reconhecer que a analogia tirada da arte humana, que serviu de base à construção da terceira Crítica, apesar de todo o seu potencial heurístico, claudica por fim. E assim se afirma a transcendência da natureza relativamente às nossas capacidades de compreendê-la nos processos internos da sua poética. A natureza permanecerá para os homens sempre uma Isis velada (idem; idem, p.316). Ainda assim, Kant não deixa de realçar o significado que a experiência estética da beleza da natureza tem para nos dar acesso a uma mais vasta compreensão da própria natureza, nomeadamente pela extensão que permite à consideração teleológica da natureza. Escreve o filósofo:

A beleza autónoma da natureza [selbständige Naturschönheit] descobre-nos uma técnica da natureza, que a torna representável como um sistema segundo leis 
cujo princípio não encontramos em todo o nosso poder de entendimento, a saber o de uma teleoformidade [Zweckmässigkeit] relativamente ao uso da faculdade de julgar tendo em vista os fenômenos, de tal modo que estes têm de ser apreciados não apenas como pertencentes à natureza no seu mecanismo destituído de finalidade, mas também como pertencentes à natureza pensada por analogia com a arte. Por certo, ela realmente não amplia o nosso conhecimento dos objetos da natureza, mas sim o nosso conceito da natureza, nomeadamente o que a representa como mero mecanismo, até precisamente ao conceito da mesma como arte: o que convida a profundas investigações acerca da possibilidade de uma tal forma. (idem; idem $\S 23, \mathrm{Ak}$ V, p.246)

Nisso, a experiência do belo natural é muito mais fecunda do que a experiência do sublime da natureza, pois nesta a natureza revela-se não como um poder de inesgotável produção finalizada de belas formas e de incontáveis seres vivos, mas como um caótico e incomensurável poder de destruição, como a negação de toda a conformidade a fins (ibidem). Se perante o belo da natureza somos estimulados a admirar e a amar a natureza, perante o sublime da natureza, esta impõe-se ao homem como objeto de "admiração ou respeito" (Bewunderung oder Achtung), "uma espécie de respeito" (eine Art von Achtung) (idem; idem, p.245, p.249, p.257) e suscita nele um "temor reverencial" (Ehrfurcht) (idem; idem, p.264), expressões que, no contexto da sua filosofia prática, Kant nos ensinara a reservar apenas para pessoas ou para o próprio objeto da moralidade (idem; $K p V$, Ak V, p.76). Embora o filósofo declare que "sublime é a natureza naqueles seus fenômenos cuja intuição leva consigo a idéia da sua infinidade" (idem; KdU §26, Ak V, p.255), tenta mostrar, por outro lado, que é impropriamente que atribuímos a sublimidade à natureza. Na verdade, a sublimidade que experimentamos perante certos fenômenos da natureza a que chamamos sublimes é uma sublimidade do próprio espírito, ao qual, precisamente na violência que a natureza lhe impõe, é dado experimentar sob forma sensível a sua condição suprasensível (idem; idem, § 28, Ak V, p.262). ${ }^{6}$ E assim, nesta economia de mediações e de compensações que gere a terceira Crítica, a experiência do sublime revela a sua fecundidade e pertinência não para ampliarmos o conceito de natureza como um sistema de fins, quanto para nos permitir, sob o modo estético, um vislumbre do mundo supra-sensível e, graças a ela, também a própria natureza no seu todo se torna para nós, pela incomensurável grandeza e poder com que se nos manifesta, a "exposição de algo suprasensível" (Darstellung von etwas Übersinnlichen) (idem; idem, § 29, Ak V, p.268), o "esquema" ou o símbolo estéticos do Infinito que para nós é um

6 "Also heisst die Natur hier erhaben, bloss weil sie die Einbildungskraft zur Darstellung derjenigen Fälle erhebt, in welchen das Gemüth die eigene Erhabenheit seiner Bestimmung selbst über die Natur sich fühlbar machen kann". 
"abismo" (Abgrund) (idem; idem, p.265), mas por certo apenas "uma mera exposição negativa do Infinito" (eine blosse negative Darstellung des Unendlichen) (idem; idem, p.274).

Apesar de constituírem experiências estéticas de sinal contrário, tanto a vivência do belo natural como a do sublime da natureza representam já em si mesmas a superação do sujeito e dos seus interesses a favor da natureza. Como escreve Kant, "o belo predispõe-nos para amar algo, mesmo a natureza, sem termos nisso qualquer interesse; o sublime predispõe-nos para estimá-la altamente, mesmo contra o nosso interesse (sensível)" (idem; idem, p.267). ${ }^{7}$

4. Como Kant expressa e reiteradamente o diz, é a experiência da beleza da natureza e não a experiência da beleza artística que constitui a protoexperiência estética. É ela que nos faz descobrir em nós uma nova faculdade - a faculdade de julgar reflexionante - e um novo princípio transcendental meramente subjetivo - o da conformidade a fins da natureza (teleoformidade da natureza) - Zweckmässigkeit der Natur - que constitui o próprio juízo estético ou de gosto na sua peculiar autonomia (idem; Erste Einleitung, XII, Ak XX, p.251). ${ }^{8}$ E na economia da estética kantiana e da terceira Crítica é verdadeiramente a experiência do belo natural que constitui o problema fundamental que desencadeia toda a meditação kantiana, sendo o problema da arte humana pensado já como uma extensão da solução encontrada para aquele. É por ocasião da reflexão sobre a beleza da natureza que a faculdade de julgar surpreende em si um princípio transcendental peculiar, o da teleoformidade da natureza (Zweckmässigkeit der Natur), o qual depois se revela fecundo para compreender também a própria criação artística humana e sobretudo aquela secreta arte que a natureza põe em jogo na produção dos seus seres orgânicos. Mas se a apreciação estética da natureza abre caminho à apreciação teleológica da mesma natureza, também es-

7 "Das Schöne bereitet uns vor, etwas, selbst die Natur ohne Interesse zu lieben; das Erhabene, es selbst wider unser (sinnliches) Interesse hochzuschätzen".

8 Este passo contém in nuce toda a terceira Crítica e deve ser transcrito na íntegra:: "Noch ist anzumerken: dass es die Technik in der Natur und nicht die der Kausalität der Vorstellungskräfte des Menschen, welche man Kunst (in der eigentlichen Bedeutung des Worts) nennt, sei, in Ansehung deren hier die Zweckmässigkeit als ein regulativer Begriff der Urteilskraft nachgeforscht wird und nicht das Prinzip der Kunstschönheit oder einer Kunsvollkommenheit nachgesucht werde, ob man gleich die Natur, wenn man sie als technisch (oder plastisch) betrachtet, wegen einer Analogie, nach welcher ihre Kausalität mit der der Kunst vorgestellt werden muss, in ihrem Verfahren technisch, d. i. gleichsam künstlich nennen darf. Denn es ist um das Prinzip der bloss reflektierenden, nicht der bestimmenden Urteilskraft (dergleichen allen menschlichen Kunstwerken zum Grunde liegt), zu tun, bei der also die Zweckmässigkeit als unabsichtlich betrachtet werden soll, und die also nur der Natur zukommen kann. Die Beurteilung der Kunstschönheit wird nachher als blosse Folgerung aus denselbigen Prinzipien, welche dem Urteile über Naturschönheit zum Grunde liegen, betrachtet werden müssen" (cf. idem; idem, p.244). 
ta, por sua vez, reverte sobre a visão estética. Pois a natureza poderia ser um sistema de fins e conforme a fins na sua produção e, todavia, não ter em conta o prazer estético. Ora, na sua peculiar poética, é como se a natureza tivesse tido também em conta esse aspecto a nosso favor. O filósofo não admite por certo um realismo estético da finalidade da natureza, que nos levasse a considerar esta como tendo na base das suas produções, para além da idéia de um fim de utilidade e de compatibilidade de uns seres com os outros, também uma idéia de beleza à qual aquelas produções se adequassem e tendo ainda em vista que isso pudesse vir a ser contemplado e apreciado por alguém e precisamente pelo homem. No § 58 da Crítica do Juízo, Kant considera, todavia, que inúmeras belas formações que se encontram em todos os reinos da natureza (mineral, vegetal e animal) falam muito alto a favor dessa hipótese, embora por outro lado devamos pensar que todas essas belas formações são apenas o efeito de fortuitas e caóticas combinações químicas e de meros processos mecânicos. Mas isso só torna o fenômeno ainda mais surpreendente e digno de admiração. A finalidade estética que atribuímos à natureza é meramente ideal, e não real, e o juízo estético sobre a beleza da natureza é meramente subjetivo, não determinante do objeto, mas reflexionante para o próprio sujeito na sua apreciação do objeto.

Poderíamos pensar que a natureza ganharia mais se lhe atribuíssemos um realismo estético, se considerássemos que realmente ela se propõe à produção de formas objetivamente belas e que essas formas são belas apenas porque são o efeito de uma produção estética intencional da natureza. Mas não é assim. O idealismo estético kantiano aplicado à natureza não se limita a este ou àquele produto ou forma naturais que revelassem certas qualidades objetivas de beleza. Mas precisamente porque não está limitado por isso, pode ele sublimar esteticamente qualquer aspecto da natureza. Não se trata de considerar o mundo ou a natureza como sendo realmente belos, mas de dispor o espírito para embelezar o mundo. ${ }^{9}$ Como diz Kant, na apreciação estética que sobre a natureza fazemos, não está em causa o que ela é ou o que para nós é um fim, mas o modo como a acolhemos, pois poderia até dar-se o caso de haver uma conformidade a fins objetiva da natureza, segundo a qual ela tivesse produzido as suas formas belas para o nosso prazer, sem que nós captássemos essas formas com uma teleoformidade subjetiva que nos desse prazer e que se fundasse apenas no jogo da nossa imaginação deixada em plena liberdade. No juízo estético sobre a natureza

9 Como se diz numa Reflexão "Der aesthetische idealism würde der seyn, der nicht eine schönere Welt als die wirkliche schildert, sondern das Gemüth disponirt, die Welt verschönen" (idem; Refl. zur Logik, Refl. 230, Ak XV, p.88). "Idealism: dass alles im dem Menschen Liege, e.g. Schönheit der Welt" (idem; idem, Refl.231). 
"somos nós que acolhemos a natureza com favor, sem que pela sua parte ela nos indique o menor favor" (wo es Gunst ist, womit wir die Natur aufnehmen, nicht Gunst, die sie uns erzeigt) (idem; KdU, Ak V, p.350). E, todavia, noutro passo da obra, Kant reconhece que esse favor que fazemos à natureza de considerá-la bela, é, por assim dizer, a recíproca resposta ao livre favor que a natureza prodigamente nos faz de, para além de nos ser realmente útil, ainda se nos mostrar generosamente bela:

Podemos considerar como um favor que a natureza teve em relação a nós, o fato de ela ter distribuído tão ricamente, para além do útil, ainda a beleza e o encanto [Schönheit und Reize], e por isso amá-la, tal como por causa da sua incomensurabilidade a contemplamos com respeito e nos sentimos nós próprios enobrecidos nesta contemplação: precisamente como se a natureza tivesse montado e adornado o seu majestoso teatro precisamente com esta intenção. (idem; idem § 67, Ak V, p.380)

Graça e amabilidade com amabilidade e graça se pagam! Em nota a esta passagem, Kant formula ainda mais explicitamente esta nova relação graciosa entre o homem e a natureza, entre a natureza e o homem, mostrando como a contemplação estética e a apreciação teleológica da natureza se completam na sua reciprocidade:

Na parte estética foi dito: nós olhamos a bela natureza com favor, na medida em que na sua forma temos um prazer completamente livre (desinteressado). Pois neste simples juízo de gosto não se tem de modo nenhum em atenção para que fins estas belezas naturais existem: se para nos despertarem um prazer, ou se sem qualquer relação a nós como fins. Num juízo teleológico, porém, temos também em atenção esta relação e por isso podemos considerar como um favor da natureza o fato de ela, mediante a exibição de tantas formas belas, ter querido ser favorável à cultura. (ibidem)

O privilégio da experiência estética da natureza no pensamento estético de Kant revela-se ainda a outros níveis. Nomeadamente, na sua originária e essencial solidariedade com o sentimento moral e até com o sentimento religioso. O § 88 da terceira Crítica sugere uma gênese moral do juízo estético a respeito da natureza. Kant diz aí que com toda a probabilidade foi o interesse moral que, a princípio, despertou a atenção para a beleza e os fins da natureza e, depois, esse interesse moral viria a ser fortalecido por essa consideração estética (idem; idem § 88, Ak V, p.459). E, noutro lugar da mesma obra, aponta a semelhança que a experiência estética e teleológica da natureza - a admiração da beleza e a emoção despertada pela consideração da grande diversidade de fins da natureza - tem com um sentimento religioso e com um sentimento moral:

A admiração da beleza [Bewunderung der Schönheit] bem como a emoção [Rührung] suscitada pelos fins tão diversos da natureza que um espírito que reflete 
está em condição de experimentar antes mesmo de possuir uma clara representação de um autor racional do mundo, têm em si qualquer coisa de semelhante a um sentimento religioso. Elas parecem agir sobre o sentimento moral (de reconhecimento e de veneração [der Dankbarkeit und der Verehrung] relativamente àquela causa de nós desconhecida) por uma espécie de apreciação desta beleza e destes fins que seria análoga à apreciação moral da mesma [durch eine der moralischen analoge Beurtheilungsart], suscitando no espírito idéias morais, quando causam aquela admiração que está ligada a um interesse que é de longe muito maior do que aquele que pode produzir uma contemplação simplesmente teórica. (idem; idem, p.482) ${ }^{10}$

Kant, que apresentara justamente a experiência da beleza natural, a de uma flor selvagem ou a de uma concha de molusco, como exemplos de uma beleza livre (frei) e autónoma (selbständige), parece comprometer agora a autonomia do juízo estético associando-o assim tão intimamente ao sentimento moral e até ao sentimento religioso. Na verdade, porém, o que ele deste modo põe em evidência é a organicidade do espírito na espontânea harmonia das suas faculdades.

O parágrafo 42 da Crítica do Juízo é o mais enfático na explícita afirmação da primazia da vivência estética da natureza sobre a vivência estética da arte. Nos primeiros parágrafos da Analítica do belo, Kant tinha caracterizado o sentimento estético da beleza como um sentimento desinteressado, mas defronta-se agora com uma particularidade que a beleza da natureza revela relativamente à beleza da arte, a saber, que, ao contrário desta, aquela

suscita no homem um interesse imediato de natureza intelectual e isso, quando é habitual e quando associado à contemplação da natureza, constitui um sinal distintivo de uma boa alma ou, no mínimo, indica uma disposição de espírito favorável ao sentimento moral. (idem; idem, p.298) ${ }^{11}$

Páginas adiante, insiste na mesma idéia:

O espírito não pode meditar sobre a beleza da natureza sem ao mesmo tempo se achar interessado nisso. Este interesse, porém, é moral por parentesco [der Verwandtschaft nach], e aquele que toma interesse no belo da natureza só o toma enquanto tem já bem fundado o seu interesse no moralmente bom. (idem; idem, p.300)

10 Em carta a J.F.Reichardt, de 15 de Outubro de 1790 (idem; Ak XI, 228), Kant, ao mesmo tempo que confessa a dificuldade de investigação da faculdade do gosto (so schwer zu erforschenden Geschmacksvermögen), coloca claramente por base do sentimento estético o sentimento moral, explicitando a intenção principal da sua Crítica do Juízo nestes termos: "Eu limitei-me com isso a indicar que sem sentimento moral não haveria para nós nada belo ou sublime" (Ich habe mich damit begnügt, zu zeigen: dass ohne sittliches Gefühl es für uns nichts Schönes oder Erhabenes geben würde).

11 Kant utiliza aqui, em contexto estético, a mesma linguagem que usara na Fundamentação da Metafísica dos Costumes para designar o interesse moral ou prático, igualmente caracterizado como um "interesse imediato" (unmittelbares Interesse) (idem; Grundlegung, Ak IV, pp.459-60). 
Aliás, esta arqueologia moral do sentimento estético da natureza já havia sido abundantemente exposta por Kant a respeito do sentimento do sublime: "O prazer do sublime da natureza [...] pressupõe um outro sentimento - o da própria destinação supra-sensível -, o qual, por obscuro que possa ser, tem um fundamento moral" (idem; idem, p.292).

A experiência estética da natureza - seja a da sublimidade seja a da beleza - torna-se assim revelação, em registo sensível, duma mensagem que é da ordem do supra-sensível. Pela mediação da vivência estética e da contemplação teleológica, a natureza é como que sublimada, adquire dimensão de transcendência e torna-se epifania do Absoluto na sua forma moral. E o filósofo crítico não tem sequer receio de restaurar em pleno século das Luzes uma linguagem que é muito próxima da que encontramos em certos pensadores medievais, lendo as formas da natureza (e até nas variações da luz, das cores e dos sons) como se fossem um "vestigium dei", como "vestígio" (Spur) ou "sinal" (Wink) de algo transcendente, como uma "escrita cifrada mediante a qual a natureza nos fala figuradamente" (Chiffreschrift... wodurch die Natur... figürlich zu uns spricht), "como uma linguagem que a natureza nos dirige e que parece ter um sentido mais elevado" (gleichsam eine Sprache, die die Natur zu uns führt, und die einen höhern Sinn zu haben scheint), que interpretamos como sendo um sentido moral (idem; idem § 42, Ak V, 302).

Neste mesmo parágrafo, o filósofo não teme transgredir ainda outros pressupostos da sua doutrina estética. Para Kant, o juízo estético, além de ser desinteressado, é meramente subjetivo, na medida em que é uma vivência do sujeito a qual consiste na mera apreensão da forma do objeto, abstraindo não só do que o objeto é em si mesmo como até da sua própria existência, que nos é, enquanto tal, indiferente. Ora, na experiência estética da natureza essa abstração e indiferença são impossíveis. É como se a dimensão meramente subjetiva do juízo estético ganhasse aqui uma dimensão objetiva, graças à qual o nosso interesse intelectual pela bela natureza nos leva não só a admirar, a respeitar e a amar a natureza, que é objeto da nossa contemplação, mas também a querer que dela nada se perca, a deixá-la na sua existência e autonomia. Mas esse imediato interesse intelectual pela beleza da natureza subsiste apenas na medida em que seja natureza ou natural o objeto da nossa contemplação, ou seja pelo menos assim tido por nós como tal. ${ }^{12}$

A passagem que a seguir se transcreve é, porventura, em toda a obra de Kant, aquela onde melhor se mostra o modo como, numa perspectiva kantiana, se poderia entender a fecundidade da contemplação estética da

12 "Es muss Natur sein, oder von uns dafür gehalten werden, damit wir an dem Schönen als einem solchen ein unmittelbares Interesse nehmen können" (idem; KdU § 42, Ak V, 302). 
natureza, que se coloca no ponto de vista do sujeito, para aquilo a que hoje chamamos uma perspectiva ecológica, que se colocasse no ponto de vista da natureza. Escreve Kant:

Aquele que solitariamente (e sem a intenção de querer comunicar as suas observações a outros) contempla a bela forma de uma flor selvagem, duma ave, dum inseto, etc., para os admirar, para os amar, e num espírito tal que ele não admitiria de bom grado a sua perda na natureza em geral, mesmo quando, longe de que a existência do objeto lhe faça ver alguma vantagem, ele disso tirasse antes prejuízo, esse toma um interesse imediato e a bem dizer intelectual pela beleza da natureza. Isso significa que não só o produto da natureza lhe apraz pela sua forma, mas também que a existência dele lhe apraz, sem que qualquer atrativo sensível tome parte neste prazer ou que a isso se associe um qualquer fim. (idem; idem, p.299)

Esta passagem mostra como a perspectiva estética se excede e se pode transformar em consciência ecológica. Mas deixa ver também o quanto a perspectiva ecológica pode aprender da fecunda lição do pensamento estético de Kant. A atitude estética em relação à natureza, tal como Kant a concebe, parece cuidar melhor da natureza, amando-a e respeitando-a, do que qualquer outra. Porque não se funda numa qualquer teoria acerca da natureza ou no que se sabe ou julga saber a respeito dela, mas na atitude humana, numa peculiar disposição do espírito em relação à natureza. Ora é esta mediação humana e até a presença humana que em certas formas de pensamento ecológico se pretende excluir, como se o homem não fosse também ele próprio um ser da natureza e um elemento dos seus sistemas ecológicos!

5. Gostaria, para concluir, de mostrar com alguns breves apontamentos como as perspectivas abertas pela terceira Crítica relativas à vivência estética da natureza podem iluminar aquilo a que atualmente se chama a "ética da natureza" ou a "ética ambiental" e o que nestas se visa, a saber, a responsabilidade ética do homem perante a natureza. Como veria Kant este problema que atualmente é tão agudamente sentido? Será que a natureza (seja a natureza animal e vegetal, ou a natureza material e mineral) pode ser encarada como sujeito de direitos e está em condições de poder reclamar que o homem considere esses direitos como seus deveres próprios?

À primeira vista, a contribuição de Kant para o tema é decepcionante. Nos escassos lugares da sua obra onde aborda expressamente a questão, o filósofo é peremptório: o homem não tem deveres a não ser relativamente ao homem (a ele mesmo ou aos outros homens) e todos os deveres que se possam pensar relativamente a outros seres que não o homem só indiretamente o são, sendo diretamente apenas deveres do homem em relação a si próprio ou à própria humanidade. A posição kantiana pode parecer formalista: é a própria noção de relação ética e de relação jurídica o que impede que se 
fale com propriedade de uma "ética da natureza" ou duma "ética animal", de "direitos da natureza" ou de "direitos dos animais" (veja-se Denis, 2000; Wood, 1998). Segundo Kant, tais expressões laboram numa sub-repção, que consiste em fazer valer univocamente para o todo da natureza um tipo de relações que só tem significado e pertinência no âmbito propriamente inter-humano e interpessoal. Mas se o homem não tem, propriamente falando, deveres para com a natureza, significa isso que não tem qualquer responsabilidade pela natureza?

De modo nenhum se pode concluir tal. Embora tenha de esclarecer-se em que consiste a responsabilidade do homem e qual o seu real alcance. Ela só pode pensar-se a uma escala humana e ainda aí muito limitada. Ainda aqui pode a perspectiva estética e teleológica iluminar o teor e os limites da peculiar responsabilidade do homem pela natureza orgânica ou inorgânica. No seu Curso de Geografia mas sobretudo na Segunda Parte da Crítica do Juízo, Kant mostra em que sentido o homem - que é ele mesmo também um membro da cadeia dos fins da natureza que esta usa como um meio para os seus fins - pode contribuir, com aquilo que lhe é próprio - a razão esclarecida e a decisão sensata -, para a gestão sustentável dos frágeis equilíbrios sistêmicos da natureza (Kant 1959-2002; Physische Geographie, Ak IX, p.253). Pensada no ambiente de uma visão estética e teleológica, a responsabilidade do homem pela natureza entende-se menos num sentido moralista ou jurídico e mais no sentido de uma mudança radical da atitude humana frente à natureza, a qual passe do confronto agressivo ao diálogo, da dominação voluntarista à atenção vigilante e respeitadora, da exploração e usufruto destruidor à disponibilidade para aceitar e agradecer o dom, a graça e os favores que a natureza espontânea e prodigamente nos dispensa, da mera contabilização calculista do lucro para a contemplação desinteressada, ou ainda para tomar interesse no que nela nos parece inútil, sem interesse, ou mesmo desagradável, cuidando para que nada se perca de quanto nela existe. A consideração teleológica e estética não anula, mas relativiza na raiz e tempera a atitude científico-técnica e até a atitude jurídico-moral do homem para com a natureza. E assim podemos entender o que escreve Kant num parágrafo da sua Doutrina da Virtude, onde discute o tópico dos supostos deveres do homem para com a natureza:

No que respeita ao belo da natureza, ainda que inanimado, a tendência para o mero destruir (spiritus destructionis) é contrário ao dever do homem para consigo próprio; porque enfraquece ou extermina no homem aquele sentimento, que, embora não sendo por si apenas já [um sentimento] moral, prepara todavia este, na medida em que promove muito aquela disposição da sensibilidade que nos leva a amar algo mesmo sem ter em vista a utilidade (por ex., as belas cristalizações, a indescritível beleza do reino vegetal). (idem; $M d S$, Tugendlehre § 17, Ak VI, p.443) 
Como facilmente se reconhecerá, esta passagem ganha todo o seu alcance se colocada no contexto da ampla reflexão kantiana sobre o juízo estético a respeito da natureza e da íntima solidariedade que aí se reconhece existir entre a experiência da beleza e sublimidade da natureza e o sentimento moral, a qual nos leva a tomar interesse pela natureza - um interesse que é por certo intelectual e moral, mas de matriz estético - e até nos sentimos legitimados a pressupor que todos os seres humanos devem tomar o mesmo interesse, ao ponto de considerarmos como "grosseira e ignóbil a maneira de pensar daqueles que não têm qualquer sentimento para a bela natureza" (idem; $K d U \S 42$, Ak V, p.303).

Num seu Curso de Ética, lecionado presumivelmente entre os anos 1775 e1785, e também no contexto do desenvolvimento do tópico dos deveres em relação à natureza, Kant evoca o exemplo de Leibniz, o qual, depois de ter observado e estudado a forma e o comportamento de um pequeno verme, colocava-o de novo na folha da árvore de onde o tirara, evitando causar-lhe qualquer dano, pois lamentava destruir sem razão uma criatura que tantas coisas lhe havia ensinado. E, na continuação, o filósofo condena, como sendo totalmente imoral, o espírito destrutivo exercido sobre coisas que, não nos sendo úteis, podem ainda ser utilizadas por outros e vai ao ponto de dizer que não temos sequer o direito de destruir aquilo em que não vemos qualquer utilidade possível. Ora, entre as coisas que muitos consideram inúteis está a beleza da natureza, acerca da qual o filósofo escreve:

Nenhum ser humano deve destruir a beleza da natureza, pois mesmo quando ele próprio possa não apreciá-la, outros homens podem ainda vir a fazer uso dela. E mesmo que não faça isso em consideração das coisas mesmas, deve fazê-lo em atenção aos outros homens. (Kant, 1990, p.257)

Estas indicações mostram a íntima relação que no espírito de Kant liga a visão estética da natureza com a sua visão da responsabilidade moral e dos deveres do homem para com os animais e a natureza em toda a sua diversidade. A moral e o direito, confinados embora a um espaço de relações entre seres humanos, alargam-se pela mediação humana e inter-humana ao mundo natural numa vasta solidariedade antropocósmica. Kant não seria formalmente defensor de uma ética da Terra, de uma ética da natureza que nos impusesse o dever de respeitá-la e conservá-la. Para ele, aquilo a que impropriamente se chamam deveres relativamente aos animais e a outros seres e coisas da natureza é algo que tem sempre em vista indiretamente os deveres para com a humanidade. Mas, ao mesmo tempo, Kant indica-nos um modo possível segundo o qual a ordem ética e jurídica, sendo propriamente uma ordem humana e entre humanos, pode alargar-se à natureza animada e inanimada, sem incorrer em sub-repções ou em falácias natura- 
listas ou antropologistas, porque consciente dos limites dessa extensão. Esse modo é precisamente o que se abre pela apreciação teleológica e pela vivência estética da natureza. A perspectiva estética e a teleológica em face da natureza, de resto afins entre si, não só corrigem e educam a visão meramente técnico-científica e económico-utilitarista da natureza, como podem também temperar as formas do fundamentalismo ético-jurídico, e não só e antes de mais aquele que por vezes se atribui a Kant, como também e porventura ainda mais o de alguns proponentes das chamadas éticas ambientais e éticas da natureza e o de alguns fervorosos advogados dos direitos da natureza.

Se há na filosofia kantiana um domínio onde a natureza é reconhecida e, por assim dizer, restabelecida na sua dignidade e autonomia e até como objeto de respeito, onde inclusivamente ela própria é pensada não já apenas como um meio para qualquer fim, mas também ela mesma como um fim e como um vasto sistema de fins, esse é o domínio da vivência estética e da visão teleológica. Onde melhor se revela a dignidade, a sublimidade e até a transcendência da natureza é na vivência estética do belo e do sublime. Mediante estas duas vivências, redescobre o homem a sua mais adequada e, por assim dizer, também a mais originária atitude em relação com a natureza, a qual se traduz ora numa grata contemplação desinteressada, ora numa espécie de veneração e respeito por ela. Para além da relação jurídica e ética, para além da lógica da dominação ou do confronto, acede o homem, na vivência estética, a uma nova e qualificada relação com a natureza muito diferente daquela que se lhe abria pela ciência ou pela moral. A lógica do interesse é aqui superada pela lógica do jogo livre ou espontâneo, a lógica da obrigação pelo gracioso favor, pelo amor (ou interesse) desinteressado. O belo, dizia-nos Kant, prepara-nos para amar a natureza de um modo desinteressado e o sublime para estimá-la altamente, mesmo contra o nosso interesse. Na vivência do sublime, a natureza, seja pela sua incomensurável grandeza seja pelo seu ilimitado poder, subjuga-nos e domina-nos absolutamente, pondo em evidência a nossa insignificância e nulidade do ponto de vista físico e furtando-se não só às nossas armadilhas de apreensão representacional e cognoscitiva, mas também a todas as nossas técnicas de manipulação. Oferecendo-se aí na sua irrecusável presença, que é, ao mesmo tempo, enquanto tal irrepresentável, a natureza insinua-se mesmo como esquema do infinito e do absoluto supra-sensível, daquele mesmo absoluto e infinito relativamente ao qual a crítica da razão especulativa nos impediu o conhecimento. Pela via estética não nos é dado um conhecimento objetivo e determinado desse absoluto, mas bem se pode dizer que ele se legitima assim para o sujeito reflexionante por uma outra via que o mantém melhor na sua transcendência. Por outro lado, na vivência estética do belo natural, a natureza oferece-se espontaneamente como dádiva de sentido na prodi- 
galidade das suas formas belas, muito antes e mesmo sem que o entendimento sobre ela aplique a sua legislação informadora que lhe dê pertinência cognoscitiva. Também aqui não se alcança um conhecimento metafísico da natureza, nem se acede à revelação da sua oculta essência que fora inviabilizada pela via teorética, mas, como o próprio Kant reconhece, desse modo amplia-se o conceito da natureza e bem se pode dizer, com Luigi Pareyson, que não só a experiência da sublimidade como também a da beleza da natureza "nos permitem lançar um olhar revelador, como um golpe de sonda, sobre a profundidade metafísica da natureza" (Pareyson, 1966, p.116).

Para traduzir esta nova experiência a que o homem acede na vivência estética da natureza de nada nos serve a linguagem do domínio do homem e da sua razão sobre a natureza. É a linguagem da amabilidade, da gentileza e da cortesia, duma amabilidade, gentileza e cortesia recíprocas, pois ao livre favor que o homem faz de considerar a natureza como bela ou sublime, corresponde ela com o espontâneo favor de se lhe apresentar pródiga de formas belas, como se quisesse oferecer sempre nova matéria ao poder humano de apreciação e de prazer estéticos.

Em suma: não só a consideração teleológica da natureza como um sistema de sistemas finalizados, como sobretudo a experiência estética do belo natural e a do sublime da natureza permitem que o homem aceda a uma relação com a natureza que não é já a da posse, a do uso instrumental e a do domínio mecânico e muito menos a da agressão e da violência, e nem sequer apenas a do respeito, mas a da recíproca dependência e solidariedade, e mesmo a da gentileza, a do livre favor, a da espontânea gratuidade e doação. Todavia, não é só a natureza que nesta nova relação é reconhecida na sua dignidade e transcendência por parte do homem, mas é também o homem mesmo que, deste modo - isto é, admirando e respeitando a natureza e os seus processos finalizados e até aqueles que não revelam qualquer visível finalidade, sendo gentil e amável para com ela -, sente-se ele próprio enobrecido e surpreende em si uma nova e mais originária dimensão, como se também ele visse desse modo ampliada a sua humanidade.

SANTOS, L. R. dos. From aesthetic experience and teleological appreciation of nature to the ecological consciousness. Reading Kant's Critique of Judgment. Trans/Form/Ação, (São Paulo), v.29(1), 2006, p.7-29.

- ABSTRACT: The aim of this paper is to suggest how the kantian conception of aesthetic experience of nature can illuminate some demands posed by the actual ecological consciousness. Main topics of our exposition would be the reversible analogy Kant supposes between art and nature, the kantian concept of a "technic of nature", the recognised priority of aesthetic experience of natural beauty with- 
in kantian Aesthetics and the function that she plays in the whole architectonics of the Critique of Judgment, namely making possible the transition from aesthetic judgment of nature to the teleological appreciation and representation of nature as artist and as a great system of ends.

- KEYWORDS: Kant; Crique of Jugement; teleology; philosophy and ecology.

\section{Referências bibliográficas}

DENIS, L. "Kant's Conception of Duties Regarding Animals: Reconstruction and Reconsideration". History of Philosophy Quarterly, 17 (2000). Pittsburg, The University, 2000.

DESCARTES, R. L'Homme. Oeuvres philosophiques I (1618-1637). Paris, Garnier, 1988.

LEHMANN, G. "Die Technik der Natur". In: Idem, Beiträge zur Geschichte und Interpretation der Philosophie Kants. Berlin, Walter de Gruyter, 1969.

GADAMER, G. Die Aktualität des Schönen. Stuttgart, Reclam, 1977.

GOETHE J.W. A metamorfose das plantas. Tradução, Introdução, Notas e Apêndices de Maria Filomena Molder. Lisboa, IN-M, 1993.

"Einwirkung der neueren Philosophie". Zur Morphologie. 1820.

KANT, I. Eine Vorlesung über Ethik. Frankfurt, Fischer, 1990.

Kants Werke. Akademie Textausgabe. 29 vols. Berlin, Walter de Gruyter, 1959-2002.

PAREYSON, L. Conversazioni di estética. Milano, Mursia, 1966.

ROUSSEAU, J.J. Émile ou de l'éducation. Paris, Gallimard, 1969.

Les rêveries du promeneur solitaire. Paris, Garnier-Flammarion, 1964.

Julie ou la Nouvelle Heloïse. Paris, Garnier-Flammarion, 1967.

SANTOS, L.R. "Kant e o regresso à natureza como paradigma estético". in: Beckert, C. (org.). Natureza e Ambiente. Representações na Cultura Portuguesa. Lisboa, CFUL, 2001, pp.169-193.

SCHOPENHAUER, A. Die Welt als Wille und Vorstellung, Anhang: Kritik der kantischen Philosophie. Zurique, Diogenes, 1977.

WOOD, A.W. "Kant on Duties Regarding Non-Rational Nature". The Aristotelian Society. Suppl. 72 (1998). Londres, The society, 1998.

Artigo recebido em 12/05; aprovado para publicação em 03/06. 